\title{
BERNARD MOURALIS, Théo Ananissoh, Sony Labou Tansi, Améla et moi...
}

\section{Roberto Ferraroni}

\section{(2) OpenEdition}

\section{Journals}

\section{Edizione digitale}

URL: https://journals.openedition.org/studifrancesi/12259

DOI: 10.4000/studifrancesi. 12259

ISSN: 2421-5856

\section{Editore}

Rosenberg \& Sellier

\section{Edizione cartacea}

Data di pubblicazione: 1 avril 2018

Paginazione: 178-179

ISSN: 0039-2944

\section{Notizia bibliografica digitale}

Roberto Ferraroni, «bernard mouralis, Théo Ananissoh, Sony Labou Tansi, Améla et moi...». Studi Francesi [Online], 184 (LXII | I) | 2018, online dal 04 juillet 2018, consultato il 17 novembre 2021. URL: http:// journals.openedition.org/studifrancesi/12259; DOI: https://doi.org/10.4000/studifrancesi.12259

Questo documento è stato generato automaticamente il 17 novembre 2021.

\section{(a) $\odot \Theta$}

Studi Francesi è distribuita con Licenza Creative Commons Attribuzione - Non commerciale - Non opere derivate 4.0 Internazionale. 


\title{
BERNARD MOURALIS, Théo Ananissoh, Sony Labou Tansi, Améla et moi...
}

\author{
Roberto Ferraroni
}

\section{NOTIZIA}

BERNARD MOURALIS, Théo Ananissoh, Sony Labou Tansi, Améla et moi..., Paris, L'Harmattan, 2017, 204 pp.

1 «Le livre de Théo Ananissoh, Le soleil sans se brûler, a fait surgir en moi des interrogations et des problématiques enfouies depuis longtemps dans ma mémoire et ma conscience» (p. 44). Fin dall'introduzione, Bernard Mouralis rende il lettore partecipe delle sensazioni e dei ricordi risvegliati dalla lettura del romanzo di Ananissoh, autore togolese contemporaneo, pubblicato nel 2015. Grande esperto di letteratura africana, Mouralis dedica la sua ultima pubblicazione a un'analisi approfondita del libro di Ananissoh che lo ha profondamente colpito. Nonostante l'intero libro sia ricco di riferimenti alle esperienze personali di Mouralis, non bisogna commettere l'errore di credere che si tratti di un'opera autobiografica; a un'attenta lettura si rivela piuttosto uno studio dettagliato di storia letteraria. Il volume si presenta diviso in tre capitoli, che corrispondono a tre blocchi narrativi, nettamente diversi l'uno dall'altro dal punto di vista delle tematiche trattate in ognuno di essi.

2 Nel primo capitolo Mouralis analizza il destino letterario di Sony Labou Tansi, autore congolese morto nel 1995, così come appare in Le soleil sans se brûler, attraverso i dialoghi tra il protagonista Théo e il suo anziano professore Améla. L'immagine che ne emerge non è particolarmente gratificante per Labou Tansi, del quale si dice, usando le parole di Améla, che soltanto tre dei suoi romanzi sono leggibili: La Vie et demie, L'État honteux et L'Anté-peuple. Tutto il resto della sua produzione letteraria non vale nulla. Questo scambio di opinioni tra i due protagonisti spinge alla fine Mouralis a chiedersi se Labou Tansi non sia stato effettivamente sopravvalutato. Nella seconda parte, Mouralis si concentra sulle diverse tipologie di rapporti che si possono instaurare tra 
"maître, disciple, camarade" e ne analizza le molteplici sfumature. Di rilievo è il legame descritto tra Sony e Améla che, nonostante alcune diversità, si relazionavano come pari. Ancora più interessante è il rapporto tra Théo e il suo anziano professore Améla: all'inizio del romanzo il narratore non nutre particolare interesse ad incontrare il suo vecchio professore, ma cambierà idea una volta riscontrata la difficile situazione in cui Améla si trova nel momento della sua visita. L'atteggiamento del disciple cambia e inizia un lungo scambio dialogico, scandito dal loro peregrinare per le vie della città fino al momento della morte del maestro. Mouralis mette anche in risalto un evidente parallelismo tra il rapporto di Théo e Améla e quello dei due protagonisti di un racconto di Philippe Jaccottet, L'obscurité, che vide la luce nel 1961 (p. 118).

Nell'ultimo capitolo del saggio invece, Mouralis presenta l'opera di Améla, svelando le tre sfere di interesse in cui ha maggiormente impiegato le sue abilità di scrittore. In primo luogo il periodo delle guerre civili e della nascita dell'Impero nell'antica Roma, con una particolare attenzione riservata a due «figures radicalement inverses»: da un lato Giulio Cesare, "celui qui rétablit l'ordre et redonne à Rome une organisation administrative et un État» riprendendo in un certo senso «l'argumentation par les régimes fascistes» (pp. 147-148); dall'altro lato Cicerone che, al contrario, rappresenta «tous les défauts inhérents au parlementarisme et notamment l'impuissance à laquelle se trouvent réduits tous ceux qui s'enferment dans le formalisme juridique et qui sont incapables de voir que le pays a désormais besoin d'un État Nouveau» (p. 148). In seguito vengono presentati i suoi studi sulla letteratura francese dell'Ottocento, in particolar modo quelli legati a Victor Hugo, Charles Baudelaire, Gérard de Nerval e Arthur Rimbaud e le analisi delle opere di autori africani del Novecento. Infine viene proposto un sguardo sulla sua opera poetica Les Odes Lyriques.

Nel saggio di Mouralis si può intravvedere in un certo senso un effetto di circolarità che permette alla finzione di intrecciarsi con la realtà: Charles Koffi Améla (nel racconto di Ananissoh) fa pensare al professore Janvier Améla che aveva un legame d'amicizia con Sony Labou Tansi e con Théo Ananissoh che fu suo studente. La tesi di dottorato di Ananissoh era su Labou Tansi e il suo relatore di tesi era Daniel-Henry Pageaux, che ha scritto la prefazione di questo saggio di Mouralis. Per chiudere il cerchio, Mouralis ha lavorato a stretto contatto con il professor Améla all'Università di Lomé. I ricorrenti legami con la sua vita hanno probabilmente indotto Mouralis a scrivere un saggio che, pur non essendo un'autobiografia, pone in relazione importanti autori africani contemporanei con l'io dell'autore, come d'altronde viene anticipato dal "moi" presente nel titolo. 